Cahiers d'études africaines

\title{
Ferjani, Mohamed-Chérif. - Le politique et le religieux dans le champ islamique
}

\section{Haouès Seniguer}

\section{(2) OpenEdition}

\section{Journals}

Édition électronique

URL : http://journals.openedition.org/etudesafricaines/14389

DOI : 10.4000/etudesafricaines.14389

ISSN : 1777-5353

Éditeur

Éditions de l'EHESS

\section{Édition imprimée}

Date de publication : 1 juin 2012

Pagination : 700-704

ISBN : 978-2-7132-2349-5

ISSN : 0008-0055

Référence électronique

Haouès Seniguer, "Ferjani, Mohamed-Chérif. - Le politique et le religieux dans le champ islamique ", Cahiers d'études africaines [En ligne], 206-207 | 2012, mis en ligne le 29 octobre 2012, consulté le 23 septembre 2020. URL : http://journals.openedition.org/etudesafricaines/14389; DOI : https://doi.org/ 10.4000/etudesafricaines.14389

Ce document a été généré automatiquement le 23 septembre 2020.

(c) Cahiers d'Études africaines 


\title{
Ferjani, Mohamed-Chérif. - Le politique et le religieux dans le champ islamique
}

\author{
Haouès Seniguer
}

\section{RÉFÉRENCE}

FERJANI, Mohamed-Chérif. - Le politique et le religieux dans le champ islamique. Paris,

Fayard, 2005, 353 p., bibl.

1 Mohamed-Chérif Ferjani entend examiner dans cet ouvrage les rapports entre le politique et le religieux dans le champ islamique. C'est-à-dire qu'il décortique les discours, sur le terrain politique, médiatique ou dans les milieux de la recherche savante, des adeptes d'une confusion entre les deux ordres. En l'espèce, l'auteur entreprend, dans la recherche française, un travail extrêmement important et salutaire suffisamment rare pour être salué, qui n'est pas sans rappeler, au demeurant, celui accompli par l'auteur de l'Orientalisme, Edward Saïd. Tous deux sont animés par une même volonté critique et informée s'efforçant de défaire les préjugés qui touchent tant les Arabes que les musulmans.

2 Chérif Ferjani insiste, de part en part, sur l'idée-force selon laquelle l'islam et les faits islamiques ne sont certainement pas enfermés dans un système total et figé, des origines à nos jours. Aussi, l'islam, au même titre que les autres religions du Livre, mériterait amplement, selon l'auteur, un traitement rigoureux de ses évolutions et adaptations au fil des âges et des espaces dans lesquels celui-ci a pu évoluer. De cette manière, l'auteur se propose, ambitieusement, sur la base d'une exploration sémantique, historique et théologique méticuleuse, de rompre avec des lectures essentialistes, culturalistes et ethnocentristes qui font florès, aussi bien dans la presse écrite ou télévisuelle que sur la scène académique ou universitaire. 
3 Le chercheur explore et exhume ainsi les événements fondateurs de l'islam aussi bien d'ordre religieux que d'ordre politique, en en indiquant par ailleurs les principales lignes de clivages doctrinales et idéologiques. À l'appui de sa thèse centrale, il indique, de manière détaillée, que l'islam serait éminemment pluriel tant du point de vue des dogmes, que de celui de ses incarnations historiques, des applications politiques, sociales et sociétales qu'il a connues. Ce qui est matière à pourfendre tout point de vue monolithique sur le sujet.

4 Il recense les nombreuses théories politiques passées et contemporaines. À ce titre, les mérites de ce livre sont nombreux au regard de la matière exploitée, et ouvre de multiples perspectives heuristiques, dans la mesure où le politologue essaie de casser le prisme déformant des essentialismes qui conduisent à une négation de l'histoire et de la pluralité des faits islamiques. Laquelle est à l'origine des conflits humains et de tentations de rejet de l'Autre en général et du musulman en particulier.

5 Mais d'où proviennent alors tant de malentendus qui entretiennent la vision d'un islam irréductiblement hostile, de la même façon que ceux qui s'en réclament, à une séparation des ordres spirituel et temporel? Qui en sont les principaux architectes? Telles sont les questions que soulève l'auteur et auxquelles il tente de répondre au fil des pages.

6 La politisation de l'islam procèderait moins du texte lui-même, en soi, que de lectures partielles, partiales, essentialistes ou encore d'interprétations tronquées, aussi bien de la part d'islamologues ou (néo)orientalistes que de la part de certains militants, théologiens, intellectuels musulmans ou penseurs de l'islam. Selon Chérif Ferjani, toutes ces lectures relèveraient d'un travestissement manifeste des sources scripturaires, des traditions rapportées de l'islam et du vécu des musulmans. Aussi, à contre-courant de ce genre de lecture, le politiste explore, en sus de l'histoire des hommes de l'islam ou musulmans, la sémantique coranique et dévoile, en de multiples occasions, l'inanité de telles postures éminemment idéologiques, en contravention manifeste avec la teneur des textes et de leur portée linguistique originelle.

7 À cet effet, la partie "Le politique dans le Coran: "Langage politique de l'islam" ou langage de l'islam politique? » est une étape décisive dans la démonstration puisqu'elle renseigne, illustre et éclaire explicitement la problématique du livre. Le politologue passe au crible de la critique philologique, les innombrables abus de langage, précisément au moyen d'un travail étymologique élaboré et méticuleux.

8 Il met en évidence les versets, les mots du Coran censés, à tort, confirmer la consubstantialité du politique et du religieux, lesquels auraient pourtant été détournés de leurs sens et portée originels. C'est "une obsession textuelle», en sus d'une altération des significations premières des vocables coraniques tels que umma, milla, sharîa, etc. (ordinairement traduits par communauté, religion et loi), qui seraient principalement à la source de nombreuses incompréhensions et contresens, de même que, en conséquence, de certains excès politiques.

9 Le terme sharîa que l'on traduit, d'après l'auteur, tout abusivement, par loi, sousentendu loi intangible, sacrée et par conséquent inviolable, est la principale pierre d'achoppement sur laquelle butent lectures modernistes et lectures archaïques ou rétrogrades. Plutôt que de le traduire par voie, religion ou source, certains interprètes mal avisés l'érigeraient, à tort, au rang de loi, structurant de façon absolue, en tout lieu et en tout temps, la totalité des aspects de la vie sociale, religieuse, politique et 
économique des musulmans ainsi que de leurs sociétés. Et c est précisément sur ce terrain-là que les contresens seraient les plus fâcheux pour le lien social et la paix civile.

10 En définitive, un tel mélange des genres est le lot commun, toujours si l'on suit l'argumentaire du politiste, aussi bien des islamophobes que des "islamistes radicaux " qui réifient, chacun à leur manière, le monde islamique en arborant le même prisme anhistorique et en chaussant des lunettes déformantes.

Il y aurait fondamentalement des différences, pour ce qui est du Coran, entre «le prescriptif » et « le descriptif », entre " ce qui est normatif et ce qui ne l'est pas » parce qu'il ne recèlerait que 200 ou 634 versets de type normatif sur les 6236 que compterait l'ensemble du corpus. Pour l'auteur, un tel constat devrait pouvoir nous prémunir ou à tout le moins nous mettre en garde, contre tout usage politique du texte coranique.

Or chez Mohamed-Chérif Ferjani, on note, alors même qu'il s'est d'emblée fixé pour tâche principale de «reconstituer à partir de la pensée et des sociétés musulmanes, les fils conducteurs et la logique de [la] genèse ("pensée et sociétés musulmanes") sans [les] réduire à l'une, ni même à l'ensemble, de (leurs) déterminations ", le même biais qu'il reproche, à juste raison au demeurant, à ceux qu'il critique. Puisque celui-ci se répercute, nolens volens, dans son propre argumentaire, assurément à son corps défendant.

En effet, si Chérif Ferjani distingue bien le « descriptif » du " prescriptif » et rappelle que les soi-disant « versets normatifs » n'occupent, en définitive, que peu de place dans l'architectonique coranique, ne cessant par là même de dénoncer "l'obsession textuelle » de ses partisans, est-ce à dire qu'il n'y aurait pas d'autres voies (ou voix) que le choix d'un langage de l'islam politique sur le registre rigoureusement discriminatoire ou exclusiviste?

Quand il est question d'islam politique, lequel est une réalité, que l'on peut déplorer ou non, nous avons l'impression que l'analyse, sur cet aspect au moins, se raidit. Nous citerons en guise d'illustration, quelques passages au cours desquels l'islam politique tend à être homogénéisé alors que s'impose, en l'occurrence, une distinction rigoureuse des niveaux de réalité sociopolitique :

«Le feu de la colère islamiste couve sous la cendre de la répression. La corruption, les injustices, la tyrannie des régimes en place et le développement d'une culture de haine, sur fond de détérioration des conditions de vie et de frustrations de toutes sortes, sont autant d'ingrédients qui favorisent ce type de mouvements capables de passer facilement du statut de martyr à celui de héros ou de bourreau $»^{1}$.

Si Mohamed Chérif-Ferjani reconnaît volontiers que « de l'intérieur même de l'islam politique, des voix s'élèvent, de plus en plus, pour dénoncer ces oppositions manichéennes (islam/Occident, islam/modernité, islam/démocratie, islam/laïcité, etc.) et revendiquer la modernité, la démocratie, les droits humains et même la laïcité [...] », pourquoi, en ce cas, affirmer quelques lignes plus loin, que l'islamisme se résumerait et/ou se réduirait à « un projet antidémocratique (p. 232)»? Ce qu'il peut tout à fait être, cela soit dit en passant comme nous l'avons constaté, par exemple, dans le cas des Taliban en Afghanistan; d'autres illustrations du même type ne manquent pas!

Force est de constater, néanmoins, que tous les islamistes ne promeuvent pourtant pas le djihâd et l'avènement de la sharîa. Ce que l'auteur concède d'ailleurs lui-même, en maints endroits. Parmi eux, des militants sont précisément passés de l'activisme religieux, y compris violent, à l'action légaliste après ce qu'ils appellent eux-mêmes 
« les révisions » ou Muraja'ât, c'est-à-dire une modification de leur perception de l'ordre sociopolitique et l'acceptation des règles institutionnelles établies.

Ainsi, il est dommage que quatorze pages seulement, pourtant très intéressantes, soient consacrées « aux théories (politiques) traditionnelles »; et à peine plus de dix pages à l'islamisme, que l'auteur attribue essentiellement à Hassan Al-Banna, le père fondateur des Frères musulmans d'Égypte en 1928.

D'autres affirmations auraient pu peut-être être davantage étayées ou nuancées : «Il convient de signaler que l'État islamique revendiqué par les islamistes ${ }^{2}\left(c^{\prime} e s t\right.$ nous qui soulignons) se réclamant du sunnisme ne diffère du "gouvernement du théologien" [...] que par les références doctrinales" (p.233). En effet, la pluralité des trajectoires militantes au sein des mouvements de l'islam politique, de par le monde musulman, la configuration et reconfiguration incessantes des doctrines, du projet des associations et partis politiques "au référentiel islamique ", ne permettent pas de ramener le projet islamiste à la seule édification d'un État islamique.

19 Les nombreuses enquêtes de terrain montrent effectivement, soit que la variable religieuse est surévaluée dans l'appréhension de ce type de mouvements, au détriment de variables plus "profanes", politiques et identitaires, soit que les islamistes (par exemple ceux du Parti de la justice et du développement marocain ou son équivalent turc, l'AKP) ne reconnaissent absolument pas ou plus, le bien-fondé d'une quelconque posture révolutionnaire ou violente même si elle peut très bien leur survivre, du point de vue symbolique, et leur être sous-jacente, dans la posture de certains de leurs militants.

En définitive, ce sont moins les acteurs de l'islam politique qui théologisent forcément ou systématiquement leur combat politique, leurs discours, que les observateurs. Aussi, est-il besoin de signaler, que l'islamisme couvre un large spectre allant des taliban afghans à Al Qaïda, en passant par l'AKP turc de Erdogan ou le PJD de Benkirane ; autrement dit, des formules radicales à des formules plus légalistes et/ou légitimistes.

21 Cet ouvrage présente l'inestimable mérite de pourfendre l'essentialisme, le culturalisme et l'ethnocentrisme qui ont cours aussi bien chez les islamologues ou spécialistes académiques de l'islam que chez des islamistes ou autres acteurs politiques du monde musulman. Ce qui n'est pas une mince affaire. À cet égard, la démarche et l'argumentation sont profondes, retenant d'un bout à l'autre l'attention du lecteur, grâce notamment, dans un style des plus accessibles, à une exploration rigoureuse des sources scripturaires et de l'histoire. Là est le grand apport scientifique et à divers titres, citoyen et humaniste de Mohamed-Chérif Ferjani ; et ce en rupture totale avec les thèses du Choc des civilisations avancées par les néo-conservateurs américains.

Aussi, sept ans après sa parution, l'ouvrage demeure d'une grande actualité et d'une inestimable utilité scientifique. Chacun donc serait bien avisé de le lire s'il veut saisir la diversité des faits islamiques loin de tout essentialisme ou culturalisme niais. 


\section{NOTES}

1. Mohamed-Chérif FERJANI, Le politique et le religieux dans le champ islamique, Paris, Fayard, 2005, p. 19.

2. Nos italiques. 